US Army Corps

of Engineers ${ }_{\circledast}$

Engineer Research and

Development Center

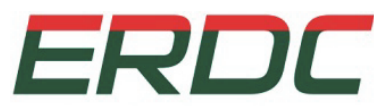

INNOVATIVE SOLUTIONS for a safer, better world

\title{
Particle Size Distributions and Attenuation on a Stratified Inner Continental Shelf
}

Richard Styles

November 2013

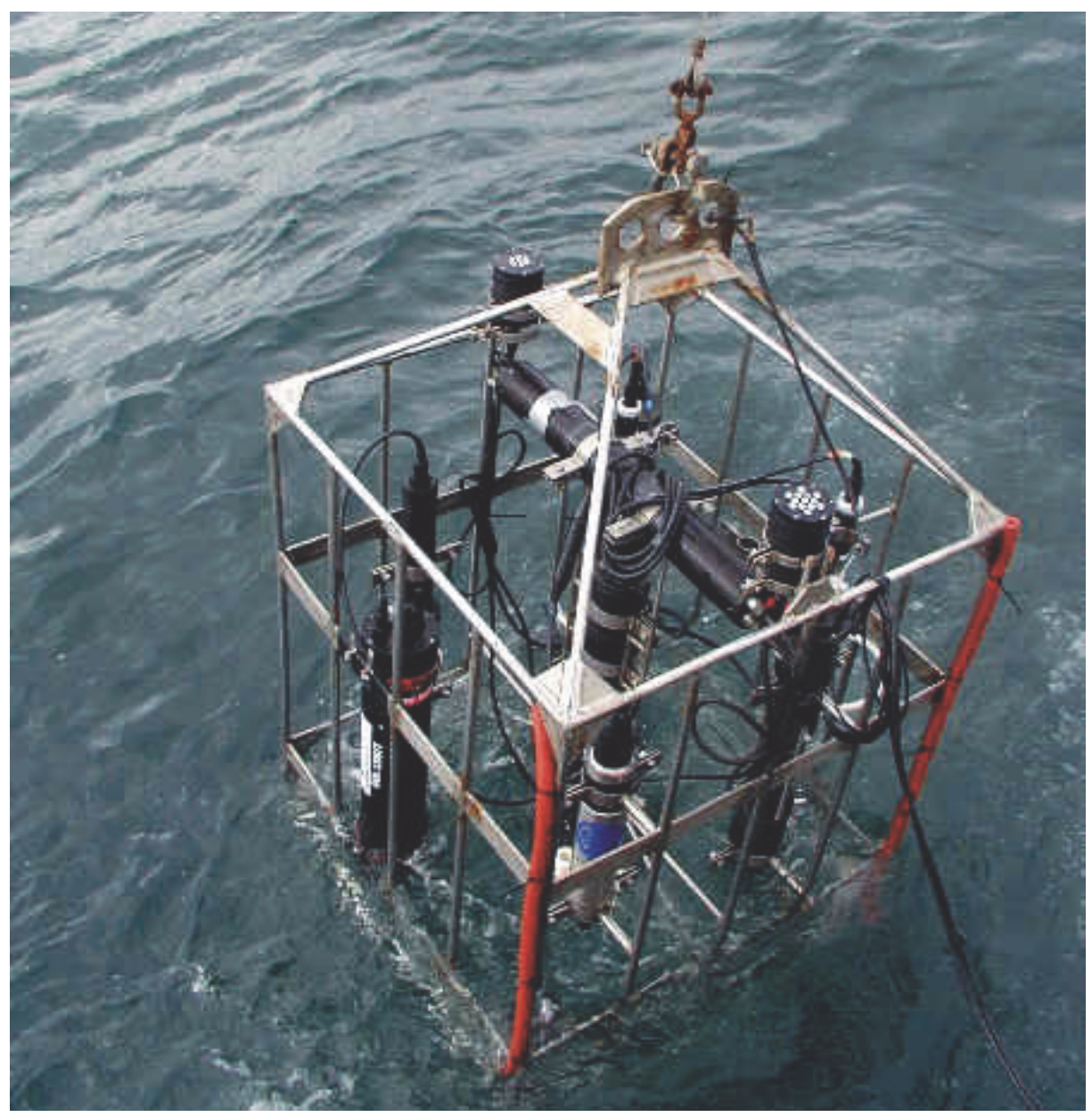


The US Army Engineer Research and Development Center (ERDC) solves the nation's toughest engineering and environmental challenges. ERDC develops innovative solutions in civil and military engineering, geospatial sciences, water resources, and environmental sciences for the Army, the Department of Defense, civilian agencies, and our nation's public good. Find out more at www.erdc.usace.army.mil.

To search for other technical reports published by ERDC, visit the ERDC online library at http://acwc.sdp.sirsi.net/client/default. 
ERDC/CHL TR-13-14

November 2013

\section{Particle Size Distributions and Attenuation on a Stratified Inner Continental Shelf}

\section{Richard Styles}

Coastal and Hydraulics Laboratory

US Army Engineer Research and Development Center

3909 Halls Ferry Road

Vicksburg MS 39180-6199

Final report

Approved for public release; distribution is unlimited.

Prepared for US Army Corps of Engineers

Washington, DC 20314-1000 


\section{Abstract}

High resolution, cross-shelf physical and bio-optical ship surveys were conducted during the summer stratified season off the southern coast of New Jersey. On 13 July 1999, a small storm passed over the study area generating the largest waves of the summer field season. Compared to prestorm levels, scattering measured with an Attenuation-Scattering at 9 wavelengths (ac-9) in depths less than $15 \mathrm{~m}$ doubled on 14 July 1999. This increase was accompanied by strong vertical mixing inshore and increases in suspended sediment concentrations measured with a Laser In Situ Scattering Transmissometer (LISST-100). A particulate load maximum was observed offshore in the thermocline. The location and vertical distribution of the maximum was unexpectedly asymmetric between the upcasts and downcasts. The observations indicated that the asymmetry was caused by particle entrainment, disaggregation, and mixing by the sampling cage housing the instruments as it was lowered and raised through the water column. A method to remove the profiling effect appeared to accurately reproduce the concentration and vertical distribution of suspended particles. The measurements suggested that some of the larger entrained particles were disaggregated to form concentrations of smaller particles on the upcasts. Given the location of the LISST within the profiling sea cage, only the downcasts produced undisturbed estimates of the vertical distribution of concentration and size classes.

DISCLAIMER: The contents of this report are not to be used for advertising, publication, or promotional purposes. Citation of trade names does not constitute an official endorsement or approval of the use of such commercial products. All product names and trademarks cited are the property of their respective owners. The findings of this report are not to be construed as an official Department of the Army position unless so designated by other authorized documents. 


\section{Contents}

Abstract................................................................................................................................. if

Figures and Tables............................................................................................................ iv

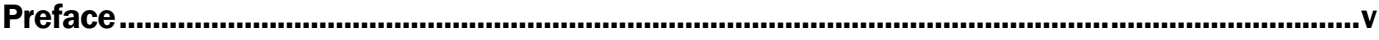

1 Introduction......................................................................................................................... 1

2 Study Site and Instrumentation ......................................................................................... 3

3 Data Processing ..................................................................................................................... 6

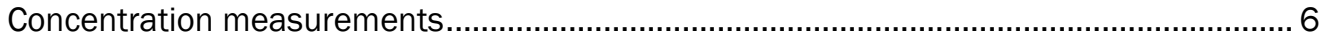

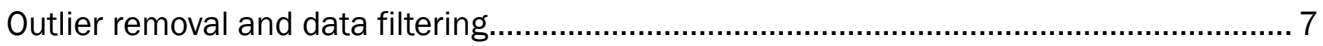

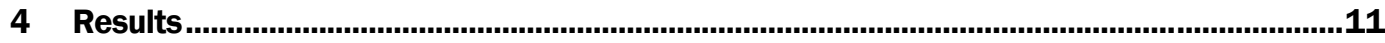

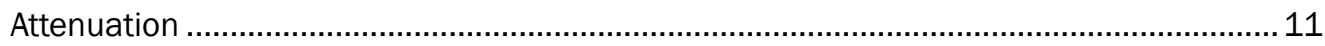

Particle concentration ............................................................................................ 11

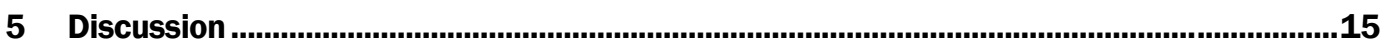

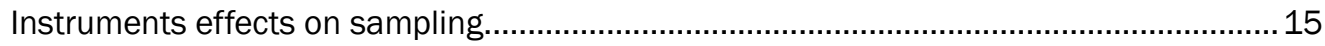

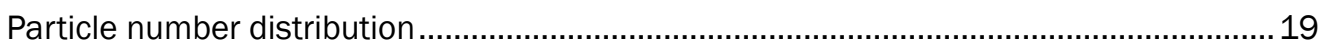

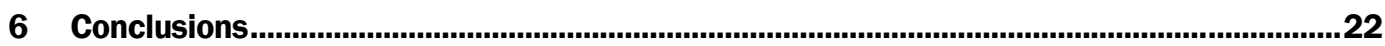

References......................................................................................................................................23

\section{Report Documentation Page}




\section{Figures and Tables}

\section{Figures}

Figure 1. The Long-term Ecosystem Observatory (LEO) located off of the southern New Jersey coast. 3

Figure 2. Wind and wave $\left(\mathrm{H}_{\mathrm{s}}=\right.$ significant wave height $)$ conditions bracketing the study period. ............. 5

Figure 3. Raw LISST concentration measurements for the 11 stations, as noted by the peaks in water depth, sampled on 14 July 1999.

Figure 4. Transmission versus concentration for the $280 \mu \mathrm{m}$ particle size class collected at the 24 m-deep station on 14 July 1999.

Figure 5. Concentrations depicted in Figure 4 as a function of the number of samples collected.

Figure 6. Attenuation at $442 \mathrm{~nm}(\mathrm{c} 442 \mathrm{~nm})$ measured by the ac-9 for the two lines sampled on 12 July 1999.

Figure 7. Cross-shelf transects of attenuation at $442 \mathrm{~nm}$ for all 3 days. Dashed lines denote temperature in degrees Celsius.

Figure 8. Mean particle concentration as a function of particle size for the 11 stations sampled on 14 July 1999........................................................................................................... 13

Figure 9. Cross-shelf transects of concentration measured from the LISST upcasts.

Figure 10. Cross-shelf transects of concentration along the A-line on 12 July 1999, as measured by the LISST downcasts.

Figure 11. Cross-shore transect of sediment concentration along the A-line on 12 July 1999, as measured by the LISST upcasts.

Figure 12. Concentration for selected particle size classes measured on the upcast. The red line is the water depth

Figure 13. Total particle number density calculated from profiles collected on 14 July 1999.

Figure 14. Comparison between scattering at $442 \mathrm{~nm}$ and particle number......

\section{Tables}

Table 1. Ship sampling stations and data reliability index for selected days during the summer field season. 


\section{Preface}

The work was performed by the Navigation Branch (HN-N) of the Navigation Division (HN), US Army Engineer Research and Development Center, Coastal and Hydraulics Laboratory (ERDC-CHL). At the time of publication, Dennis Webb was Chief, CEERD-HN-N; Dr. Jackie Pettway was Chief, CEERD-HN; and Jeff Lillycrop was the Technical Director for Navigation. The Deputy Director of ERDC-CHL was Dr. Richard Styles, and the Director was José E. Sánchez.

COL Jeffrey R. Eckstein was the Commander and Executive Director of ERDC, and Dr. Jeffery P. Holland was the Director. 


\section{Introduction}

Light transmission in inner shelf waters is strongly affected by water column hydrodynamics and particle distributions. The summer stratified season typical of many mid-latitude continental shelves produces a warm surface layer separated from the bottom by a highly variable thermocline that fluctuates in thickness and horizontal position as a function of winddriven wave and tidal mixing. Vertical stratification in the thermocline leads to a density gradient that sustains a concentrated mass of particulate matter ranging in size from silt to large organic fluff (Dickey and Williams 2001). Particulate matter in the thermocline affects the optical properties of shelf waters and can reduce vertical light penetration (Chang et al. 2001; Agrawal and Traykovski 2000; Boss et al. 2001; Sosik et al. 2001). Penetration is a major factor in evaluating and applying remote sensing technologies that rely on electromagnetic radiation as the primary sensing medium. As such, reliable in-situ measurements are required for validation, verification, and further refinement of remote sensing technologies and algorithms (Mobley 1994).

Reanalysis of previously collected data (Moline et al. 2004) suggests that established inner-shelf profiling methods, which often include a large protective housing to incase the scientific instruments, can disturb stable density layers, resulting in strong vertical mixing. This unintentional mixing disperses particles vertically giving the false impression that concentrations are widely distributed through the water column (Sullivan et al. 2010). Widespread applications of automated vertical profiling platforms that disturb the water column while sampling lead to greater potential for misinterpretation of the distribution and size of particle concentrations. Post-processing algorithms are needed to ensure that data derived from profilers is accurately interpreted.

This report focuses on results from an experimental program conducted during the 1999 summer stratified season off the New Jersey coast to examine the characteristics of optically complex coastal waters. The aim here is to examine the distribution and physical characteristics of a heterogeneous mixture of suspended particulates in the inner-shelf thermocline and to show how profiling instrumentation disrupts the natural state by dispersing particulate matter vertically. After a review of the study 
site and the procedures developed to process the optical data, results of attenuation and particle size distribution are presented. This is followed by a discussion on the vertical distribution of concentration and size distribution in the stratified offshore region and on the relationship between scattering and particle number density. Special attention is paid to the sampling technique which is shown to disturb the isopycnal layers leading to misinterpretation of the vertical distribution of the particulate layer. 


\section{Study Site and Instrumentation}

During July 1999, a series of vessel surveys was carried out at LEO (Longterm Ecosystem Observatory) as part of a Coastal Predictive Skill Experiment (Schofield et al. 2002). The purpose was to investigate the physical and optical properties of the inner New Jersey shelf during the summer stratified season in the context of recurrent, upwelling centers. Two shorenormal survey lines, denoted the A-line and the $\mathrm{N}$-line, were sampled repeatedly throughout the month of July (Figure 1). The LEO-15 site (von Alt and Grassle 1992; Glenn et al. 2000) marked the inshore limit of the A-line, and the N-line was located approximately $10 \mathrm{~km}$ north of, and parallel to, the A-line. Depending on the weather conditions, between one and five transects were sampled per day. A typical survey lasted 12 hours and covered the inner shelf from approximately the 10 to $30 \mathrm{~m}$ isobath. Each transect had a minimum of six vertical profiling stations, and all instruments sampled the full water column during each cast.

Figure 1. The Long-term Ecosystem Observatory (LEO) located off of the southern New Jersey coast. The parallel dashed lines denote the sailing line of the cross-shelf ship surveys. Water column profiles were conducted at selected locations along the A-line and $\mathrm{N}$-line throughout the summer field program.

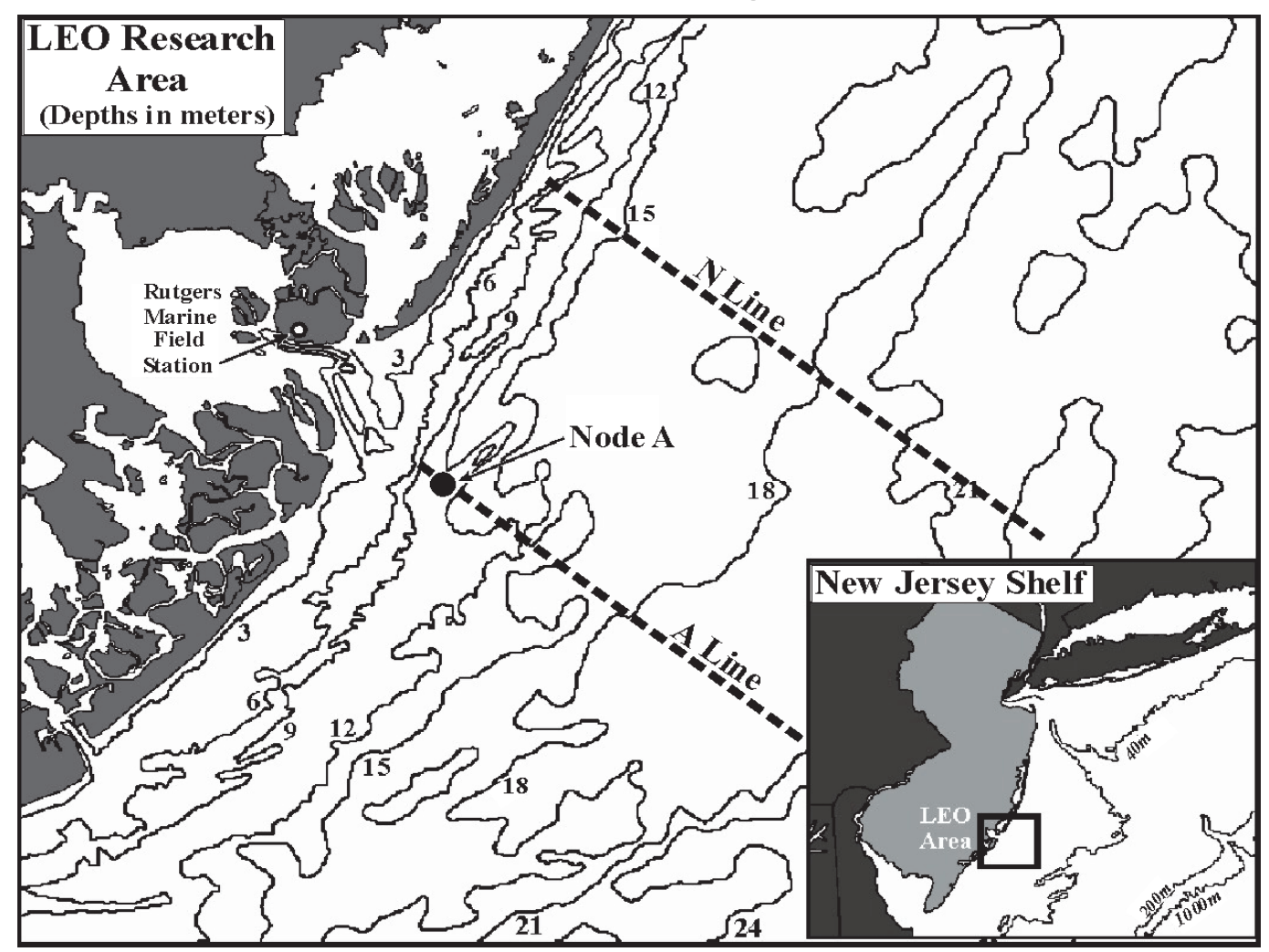


Inherent optical properties (IOPs) were collected using a nine-wavelength Wetlabs absorption/attenuation meter (ac-9). The ac-9 provided in-water estimates of absorption, attenuation, and scattering at 412, 440, 488, 520, $555,630,650,676$, and $715 \mathrm{~nm}$. The instrument was factory calibrated prior to the summer field season, and manufacturer-recommended protocols were employed to track instrument calibration. There were frequent water calibrations, and the data were temperature and salinity corrected (Twardowski et al. 1999). Particle concentration and size distribution were measured using a LISST-100 (Agrawal and Pottsmith 2000). The LISST measures in-water particle concentration and size distribution in 32 logspaced bins ranging from 2.5 to $500 \mu \mathrm{m}$. Both instruments were mounted on a protective profiling cage that also contained a CTD and other optical sampling elements (Schofield et al. 2002).

On 13 July 1999, a storm passed over the LEO area generating the largest waves of the entire month (Figure 2). The surveys were conducted the day before the peak waves were observed and two days after while wave height at Node A was still above $1 \mathrm{~m}$. Sea conditions were too rough to permit a survey on 13 July 1999. Table 1 summarizes the transects and the number of stations per transect. 
Figure 2. Wind and wave $\left(\mathrm{H}_{\mathrm{s}}=\right.$ significant wave height) conditions bracketing the study period. Shaded regions denote the times that the ship surveys were conducted. The wind vectors show magnitude and direction with a southerly wind pointing upward.

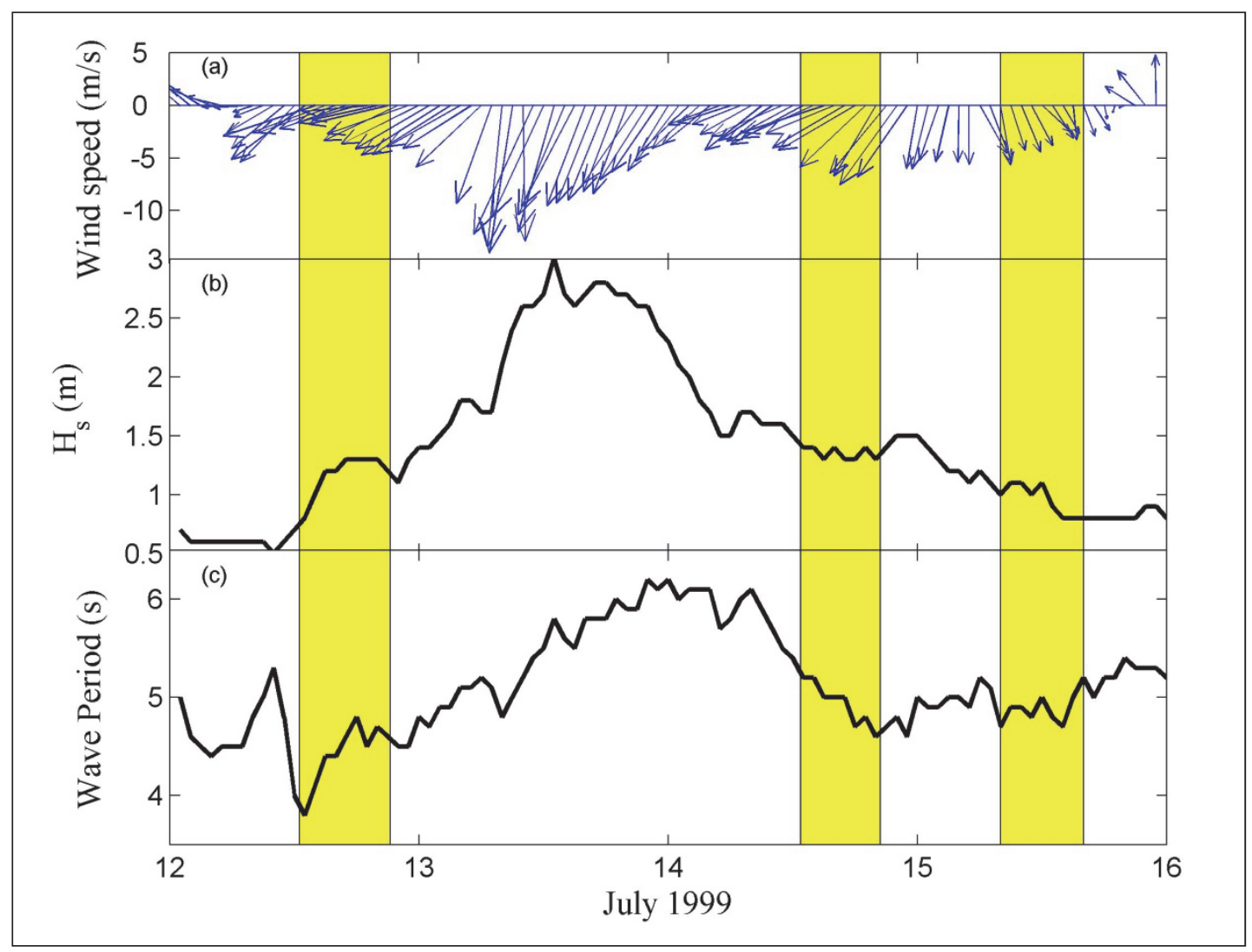

Table 1. Ship sampling stations and data reliability index for selected days during the summer field season. $\mathrm{Y}(=\mathrm{Yes})$ and $\mathrm{N}(=\mathrm{No})$ denote whether data from the particular transect are used in the analysis. Number of Stations Sampled indicates the individual profiling stations for that day.

\begin{tabular}{|c|c|c|c|c|}
\hline \multirow[b]{2}{*}{ Date } & \multicolumn{2}{|c|}{ A-line } & \multicolumn{2}{|c|}{ N-line } \\
\hline & $\begin{array}{l}\text { No. of Stations } \\
\text { Sampled }\end{array}$ & $\begin{array}{l}\text { Data Reliability } \\
\text { LISST ac-9 }\end{array}$ & $\begin{array}{l}\text { No. of Stations } \\
\text { Sampled }\end{array}$ & $\begin{array}{l}\text { Data Reliability LISST } \\
\text { ac-9 }\end{array}$ \\
\hline 12 -July & 6 & YN & 10 & $Y Y$ \\
\hline 14 -July & 11 & YY & 0 & NA NA \\
\hline 15 -July & 10 & $Y Y$ & 6 & YN \\
\hline
\end{tabular}




\section{Data Processing}

At the surface, white capping and the sudden submersion of the instrument cage as it enters the water cause aeration and bubble formation that refracts light in optical instruments. At the start of each profile, the cage was held just below the surface for approximately 2 minutes to minimize aeration and to allow the temperature sensors to equilibrate. Even so, postprocessing revealed that on a number of profiles, the downcasts data were often very noisy. As a result, only data from the upcasts were used.

\section{Concentration measurements}

The LISST measures particle size distribution for an ensemble of particles from the characteristics of their small-angle, forward-scattering properties (Agrawal and Pottsmith 2000; Agrawal and Traykovski 2000). For the narrow range of angles measured by the LISST, the refractive index plays a secondary role in describing the physics of particle scattering. Therefore, the LISST is insensitive to particle composition, which is an advantage since the water column contains a wide variety of organic and inorganic matter that cannot be distinguished without collecting a sample and disturbing the water column. The LISST computes the area distribution for each particle size class, and the volume distribution is obtained by multiplying the area distribution by the mean particle size within each size class. A conversion constant is applied to the volume distribution to give the volume concentration (C). The standard processing software supplied with the LISST computes the volume concentration in units of micro liters per liter $(\mu l / l)$. The LISST does not require calibration per se, but the laser has to be checked on a regular basis to ensure proper alignment. A procedure known as a zscat (Agrawal and Traykovski 2000) was performed on alternating days to check laser alignment referenced to the factory setting. The zscats revealed no noticeable misalignment.

Figure 3 shows concentration measured by the LISST from a cross-shelf survey conducted on 14 July 1999 . Only the upcasts were used in the analysis so that the start of each profile is identified by the corresponding increase in water depth. Particularly at the deeper stations, the data possess a number of randomly distributed concentration outliers that are sometimes three orders of magnitude larger than the remainder of the data. Outliers were noted in all size classes and all transects and were removed based on the procedure discussed as follows. 
Figure 3. Raw LISST concentration measurements for the 11 stations, as noted by the peaks in water depth, sampled on 14 July 1999. Water depth is denoted in black, and only the four largest size classes are depicted. The first sample at each station begins near the bottom so that, in accordance with the ac-9 results, only the upcasts are presented. At the offshore stations ( $>14 \mathrm{~km}$ ), concentrations that are several orders of magnitude larger than typical are noted. These uncharactersitcally large concentrations are suspected outliers.

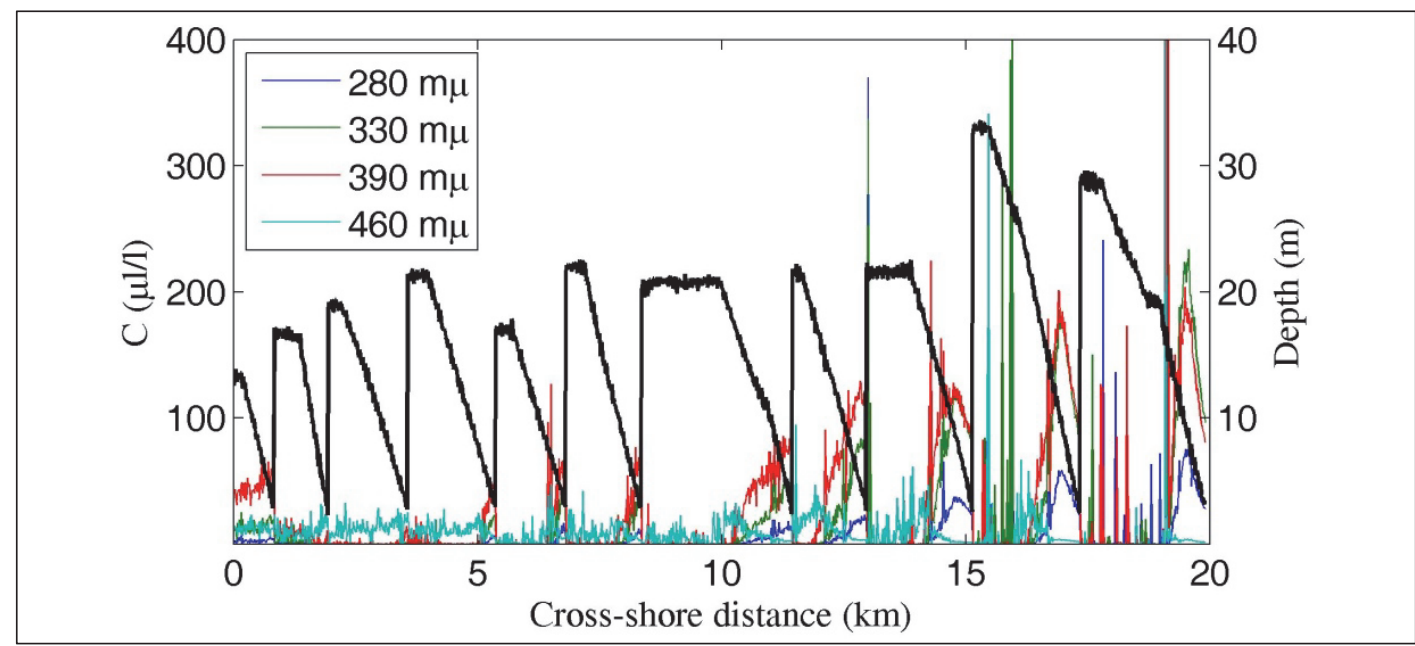

\section{Outlier removal and data filtering}

An outlier is an extreme value that is well separated from the remainder of the data (Neter et al. 1989). This definition does not necessarily imply measurement error; rather, there are some anomalously extreme values with respect to the data set as a whole. On the basis of this definition, removing the largest values in relation to the average is not a consistent approach as this does not discriminate between trends and isolated spikes. Instead, an outlier is identified by first computing the difference, as defined by $Y_{i+1}-Y_{i}$, where $Y_{i}$ is the $i$ th data point, and then removing all values greater than $R$ times the absolute value of the mean of this difference for a given profile. To maintain the same number of observation points as the original data record, the $i$ th outlier is replaced by the mean of $Y_{i+1}$ and $Y_{i-1}$. The parameter $R$ is adjustable, and increasing $R$ raises the numerical limit that defines an outlier and retains more of the original data.

As an example of the outlier removal procedure, Figure 4 is a scatter plot of optical transmission versus concentration measured with the LISST for the 24 m-deep station on 14 July 1999. The $x$-axis denotes the particle size class $(280 \mu \mathrm{m})$ that had the highest concentration, and the optical transmission is a measure of the beam attenuation caused by scattering. Increases in concentration should correlate with decreases in transmission. The results indicate a strong negative correlation between transmission and 
concentration, with the exception of a few points that are identified as anomalous by the outlier removal algorithm. For all 11 stations sampled on 14 July $1999,10 \%$ of the data were identified as outliers with $R=2$, and $1 \%$ were identified with $R=10$. The total number of outliers as a function of particle size also was computed, and the results indicated that the outliers were more or less uniformly distributed between particle sizes. In addition to outlier removal, the data were low-passed filtered. Figure 5 shows the results of these two levels of data processing (outlier removal and filtering) with $R=2$ and $R=10$ for the same station and particle size class depicted in Figure 4. The algorithm appears to accurately identify anomalous high samples that tend to greatly exceed the overall trend in the time series.

Figure 4. Transmission versus concentration for the $280 \mu \mathrm{m}$ particle size class collected at the 24 m-deep station on 14 July 1999. Transmission should correlate inversley with concentration. The two plots illustrate the sensitivity of the outlier-removal algorithm to the adjustable parameter $R$. Larger $R$ identifies fewer outliers. Plot (a) is for $R=10$, and plot (b) is for $R=2$. The pluses denote samples that have been identified as outliers.

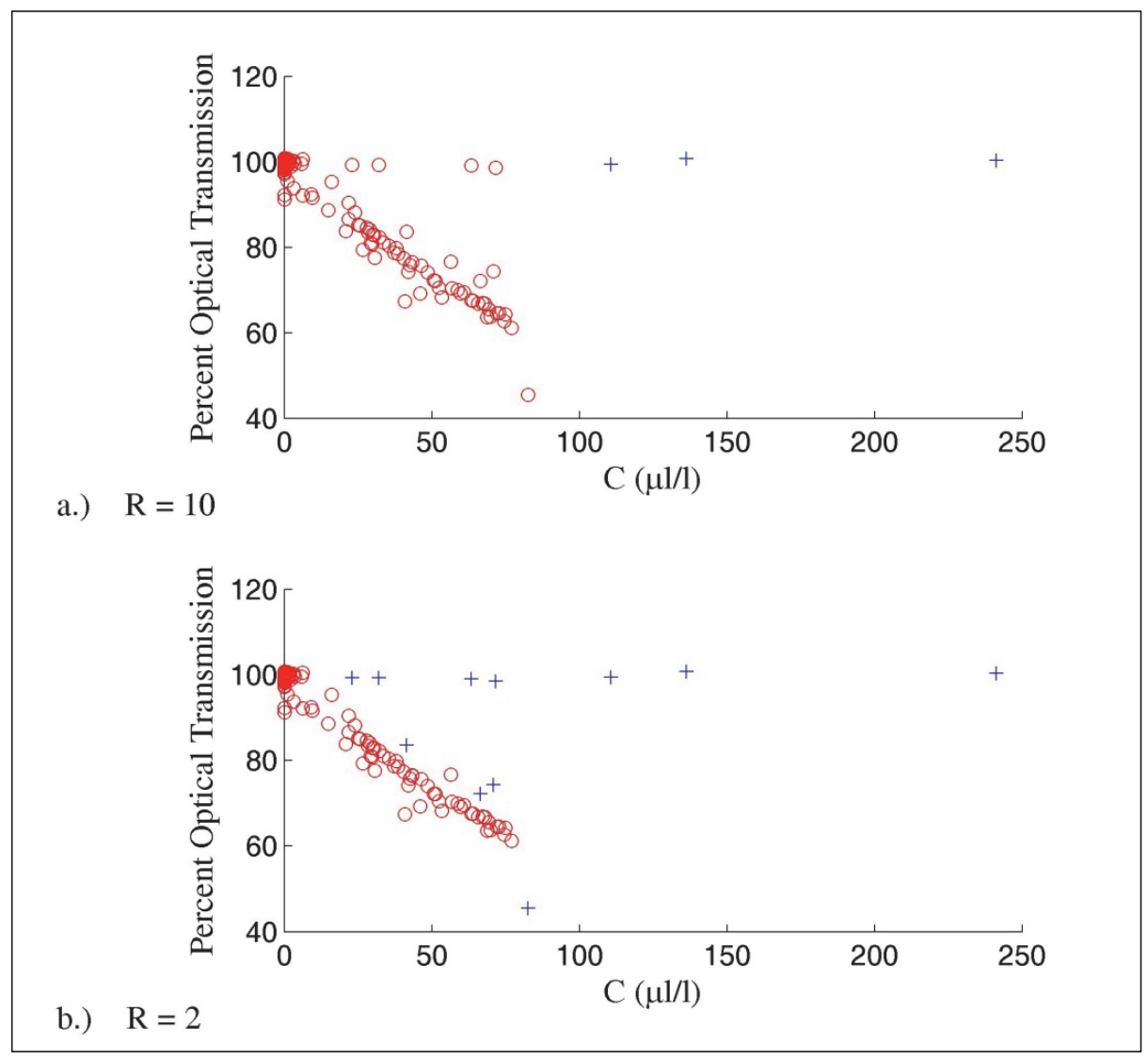


Figure 5. Concentrations depicted in Figure 4 as a function of the number of samples collected. The plots illustrate the effect of the two levels of data processing (outlier removal and filtering). Plot (a) is for $R=10$, and plot (b) is for $R=2$. The thin solid black line is the raw data; the blue dashed line is the data with outlier removal only; and the red line is with outlier removal and filtering.

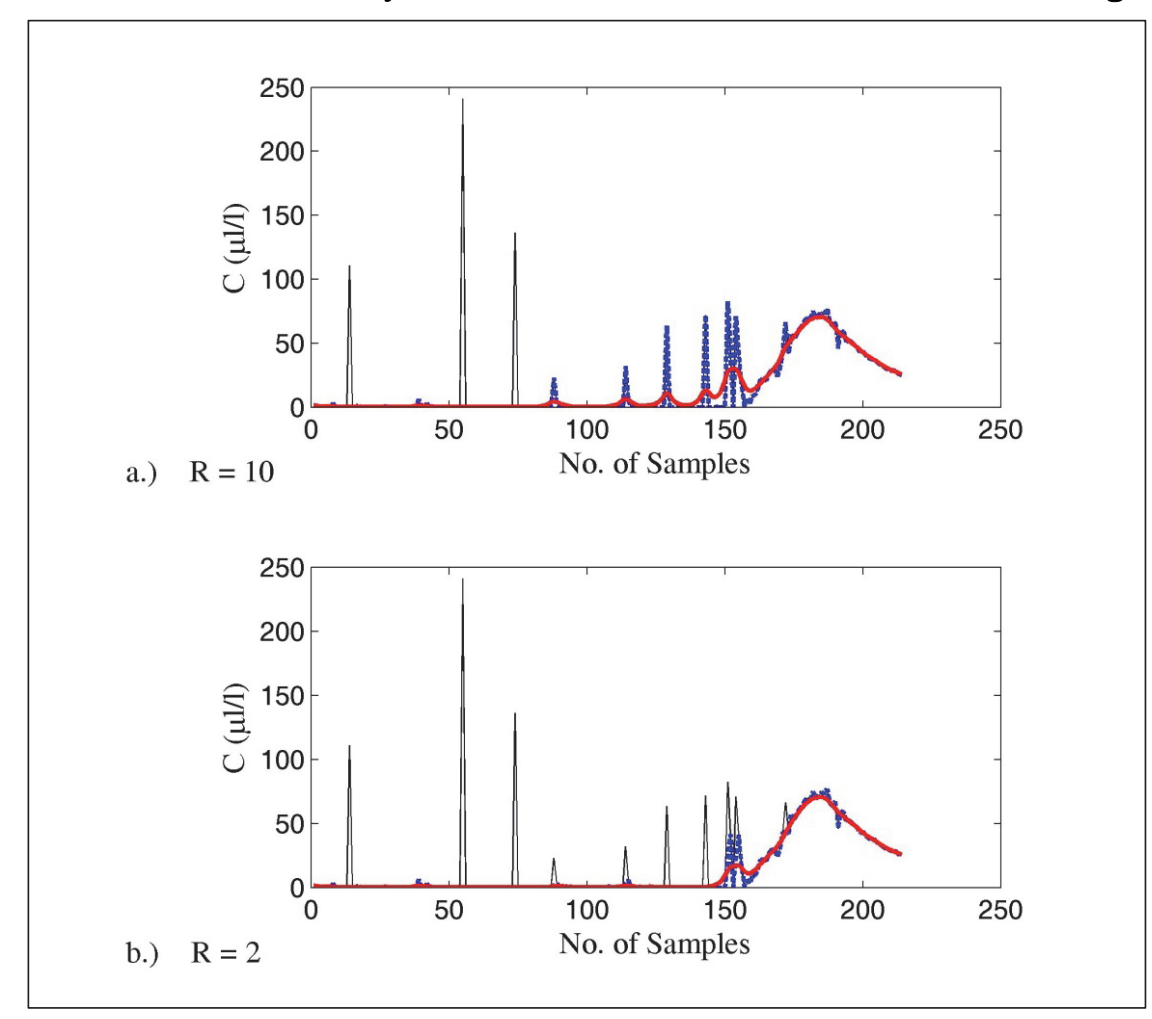

The cause of the outliers is likely due to the heterogeneous sediment environment with regions of highly variable particle concentrations consisting of isolated fluff and marine snow randomly distributed through the water column. Most of the outliers occur when the ambient concentrations are very low so that statistically there are too few particles in any one sample to render a stable mean. This is reinforced in the optical transmission results where the majority of outliers produce very little reduction in transmission, suggesting low particle numbers. Because the outlier algorithm with $R=2$ detected a greater number of anomalous data points, yet still maintained at least $90 \%$ of the original record, this value is adopted for all calculations.

Outlier removal and filtering were also applied to the optics data using the same methods as described above; however, the quality of some of the original profiles are sufficiently suspect that they are not included in the data described here. The best example of this is from ac-9 attenuation measurements collected on 12 July 1999 (Figure 6). Compared to the other 
stations, the profiles for the $2^{\text {nd }}, 3^{\text {rd }}$, and $6^{\text {th }}$ stations collected along the A-line show large-amplitude, high-frequency fluctuations. One possible cause is air bubbles that are not sufficiently expunged during the downcast. At least half of the profiles collected along the A-line on 12 July 1999, and along the N-line on 15 July 1999, showed patterns similar to those depicted in Figure 6. As a result, the ac-9 data for these two transects are not presented. The processed LISST data for these two transects do not reveal large distortions and are therefore considered reliable. Table 1 summarizes transects that produced quality data and are presented in this analysis.

Figure 6. Attenuation at $442 \mathrm{~nm}(\mathrm{c} 442 \mathrm{~nm})$ measured by the ac- 9 for the two lines sampled on 12 July 1999 . Each sawtooth pattern in water depth denotes a profile (10 profile stations along the $\mathrm{N}$-line and 6 on the A-line). Note the large amplitude fluctuations associated with the $2^{\text {nd }}, 3^{\text {rd }}$, and $6^{\text {th }}$ stations on the A-line.

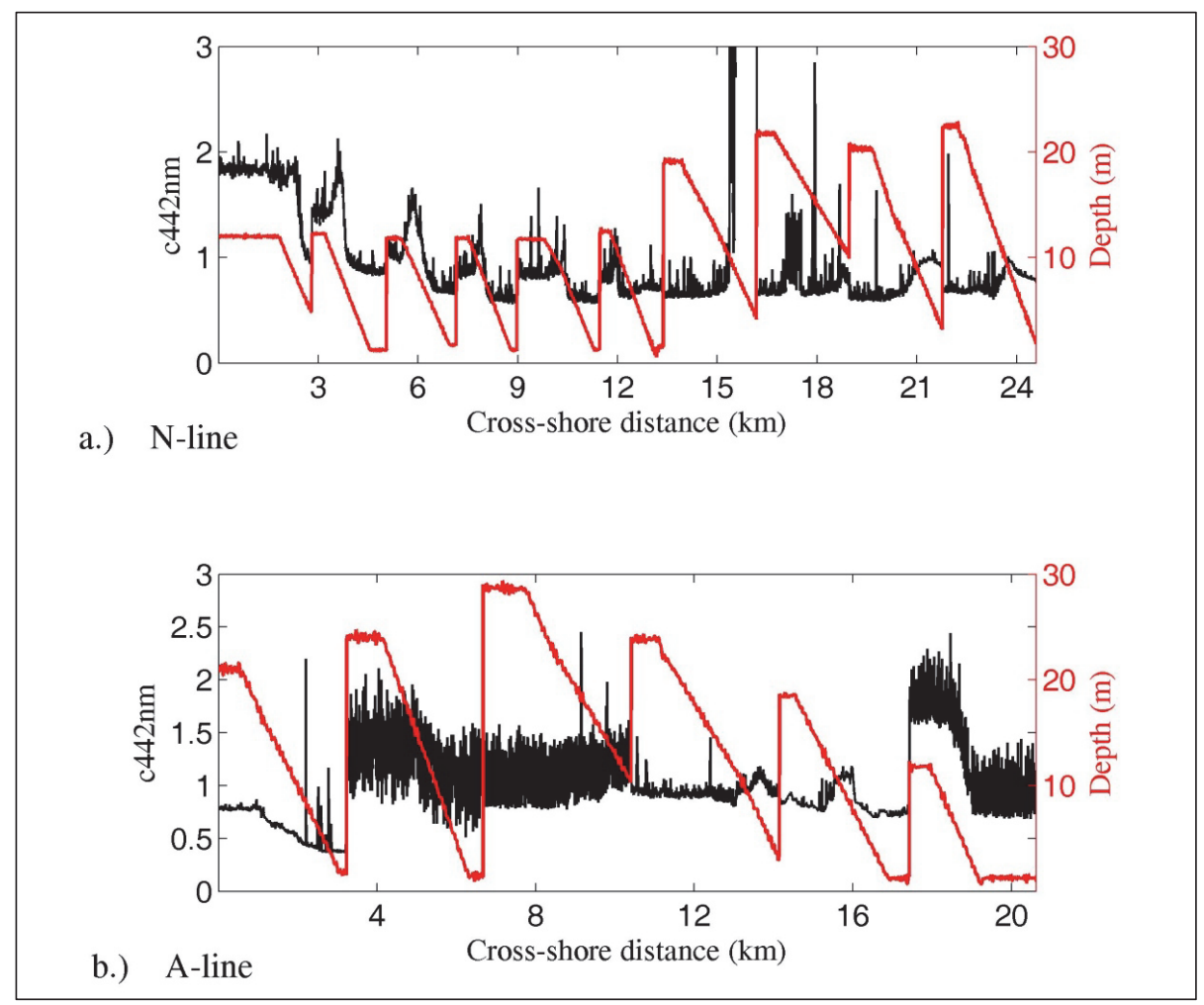




\section{Results}

\section{Attenuation}

Figure 7 depicts measured attenuation at $442 \mathrm{~nm}$, with superimposed temperature contours, for all 3 days. With the exception of a shift to lower values, the $442 \mathrm{~nm}$ cross section is characteristic of the other wavelengths. On all 3 days, attenuation is highest inshore near the bottom. On 12 July 1999, maximum attenuation is confined between the 14- and 18-degree isotherms and suggests particle trapping along density gradients. At the offshore stations on the first 2 days, attenuation is slightly increased in and above the thermocline, further suggesting particle accumulation along constant density surfaces. The influence of the hydrodynamic forcing is also evident. By 14 July 1999, the thermal structure seen on 12 July 1999 has evolved into a generally well-mixed inner region, which is indicative of increased vertical mixing due to stronger winds and waves. Compared to 12 July 1999, attenuation at the nearshore stations has increased and has become more vertically uniform, also indicative of increased mixing. On 15 July 1999, the water column remains well mixed vertically, but the water mass begins to spread farther offshore, concentrated between the 19- and 20-degree isotherms.

\section{Particle concentration}

The attenuation results suggest that concentration levels respond to the evolving hydrodynamic forcing, with increases on 14 and 15 July 1999 correlated with the higher waves and increased mixing inshore. Unlike the attenuation measurements, which showed little change in overall pattern as a function of wavelength, concentrations measured by the LISST do show a strong sensitivity to particle size. Instead of presenting the concentration results for all 32 size classes, a representative sub-sample is obtained by examining the mean distribution for the cross-shore transects as a function of particle size and then identifying discrete particle size subsets that share common characteristics. Because of the significant cross-shore variability in the attenuation, concentrations are averaged into two distinct groups representing inshore (water depth $<18 \mathrm{~m}$ ) and offshore (water depth $>18 \mathrm{~m}$ ) stations. This separates the inshore region, where the water column is shallow and well mixed, from the offshore stations, where the water column is stratified and deep. Average concentration $(C)$ as a function of 
Figure 7. Cross-shelf transects of attenuation at $442 \mathrm{~nm}$ for all 3 days. Dashed lines denote temperature in degrees Celsius.

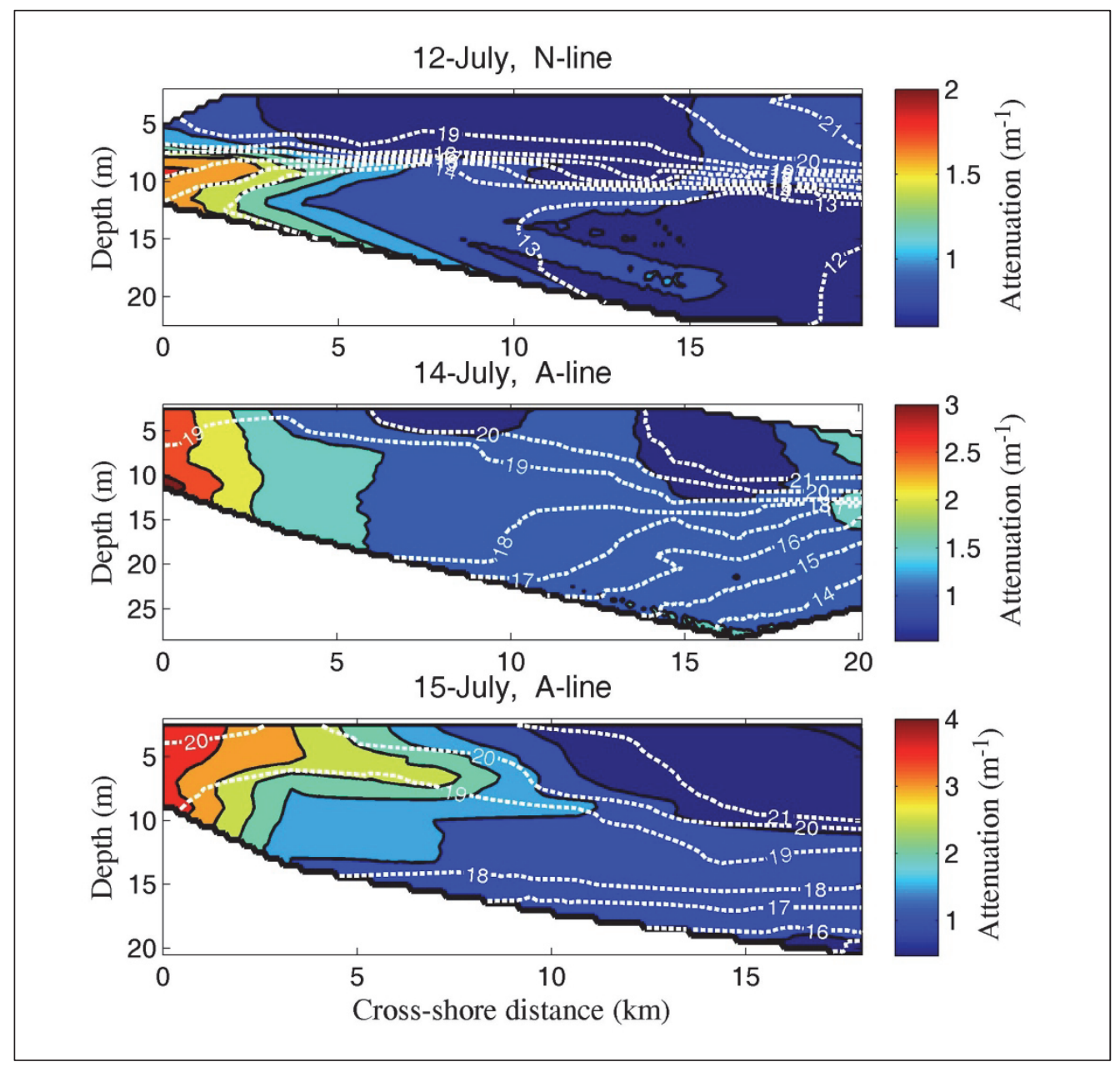

particle size for 14 July 1999 is depicted in Figure 8. The date 14 July 1999 is chosen because it had the most stations and because the relative distribution across particle sizes did not vary appreciably for the 3 days. For both inshore and offshore stations, the highest concentrations are associated with the particles in the 300 to $400 \mu \mathrm{m}$ range. A secondary peak centered between 60 and $100 \mu \mathrm{m}$ occurs offshore. For both the inshore and offshore stations, concentrations are lowest and not as variable below approximately $40 \mu \mathrm{m}$. On the basis of the localized peaks near 80 and $380 \mu \mathrm{m}$, concentrations are subdivided into three separate particle size classes: 3-40 $\mu \mathrm{m}$, 45-171 $\mu \mathrm{m}$, and 201-461 $\mu \mathrm{m}$. This breakdown corresponds to the division defined for minerals (Kennett 1982), with the smallest range corresponding to silts $(\sim 4-63 \mu \mathrm{m})$, the medium range to fine sand $(\sim 63-250 \mu \mathrm{m})$, and the largest to medium sand $(\sim 250-500 \mu \mathrm{m})$. In this context, the classification scheme does not represent particle composition as the ambient bottom stress levels are too low to resuspend medium-sized sand to produce the 
observed concentrations at the distance from the bed measured by the LISST. The smallest particle fraction $(<14 \mu \mathrm{m})$ makes up less than $1 \%$ of the total concentration and produces a negligible contribution to the total suspended load. These smallest particles are, however, important optically and will be discussed in the context of the ac-9 scattering results.

Figure 8. Mean particle concentration as a function of particle size for the 11 stations sampled on 14 July 1999. The values have been further subdivided in terms of onshore (red) and offshore (black) stations. Inspection of the concentration as a function of particle size identifies roughly three primary groups consisting of small, medium, and large particle size classes.

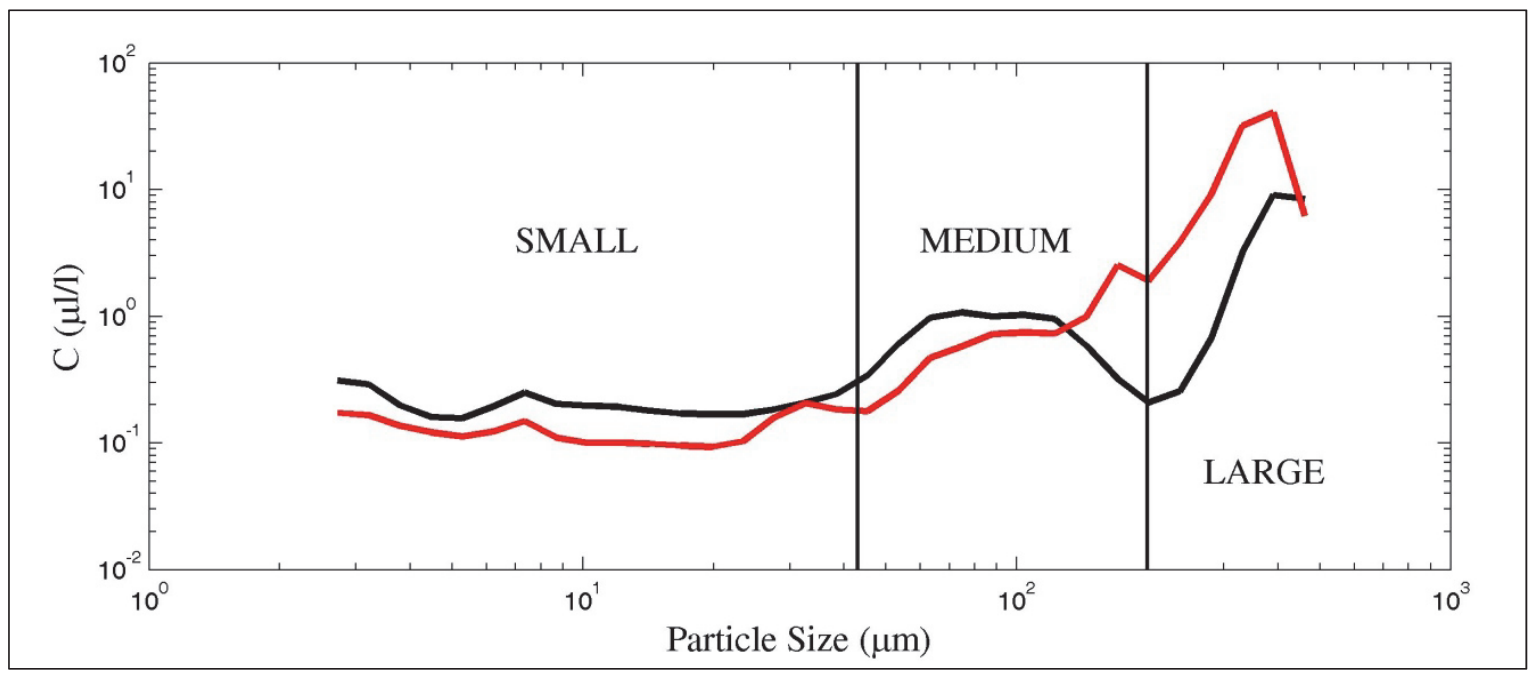

All 32 size classes are partitioned into 3 groups as defined by the distributions discussed above. Within each group, total concentration is determined by summing over each size. To compare the LISST with the ac-9, the vertical profiles for the three subclasses are reconstructed from the upcasts (Figure 9). At the shallow depths, the ensemble of the smallest particles from the LISST displays a similar pattern as attenuation from the ac-9. At the deeper depths, the largest concentrations occur in the surface mixed layer above the thermocline and are not correlated with the ac-9. 
Figure 9. Cross-shelf transects of concentration measured from the LISST upcasts. The plots in each row represent the three particle size ensembles. The dates and transects correspond to the ac- 9 attenuation results. Color bars denote concentration in $\mu / / I$, and temperatures are in degrees Celsius.

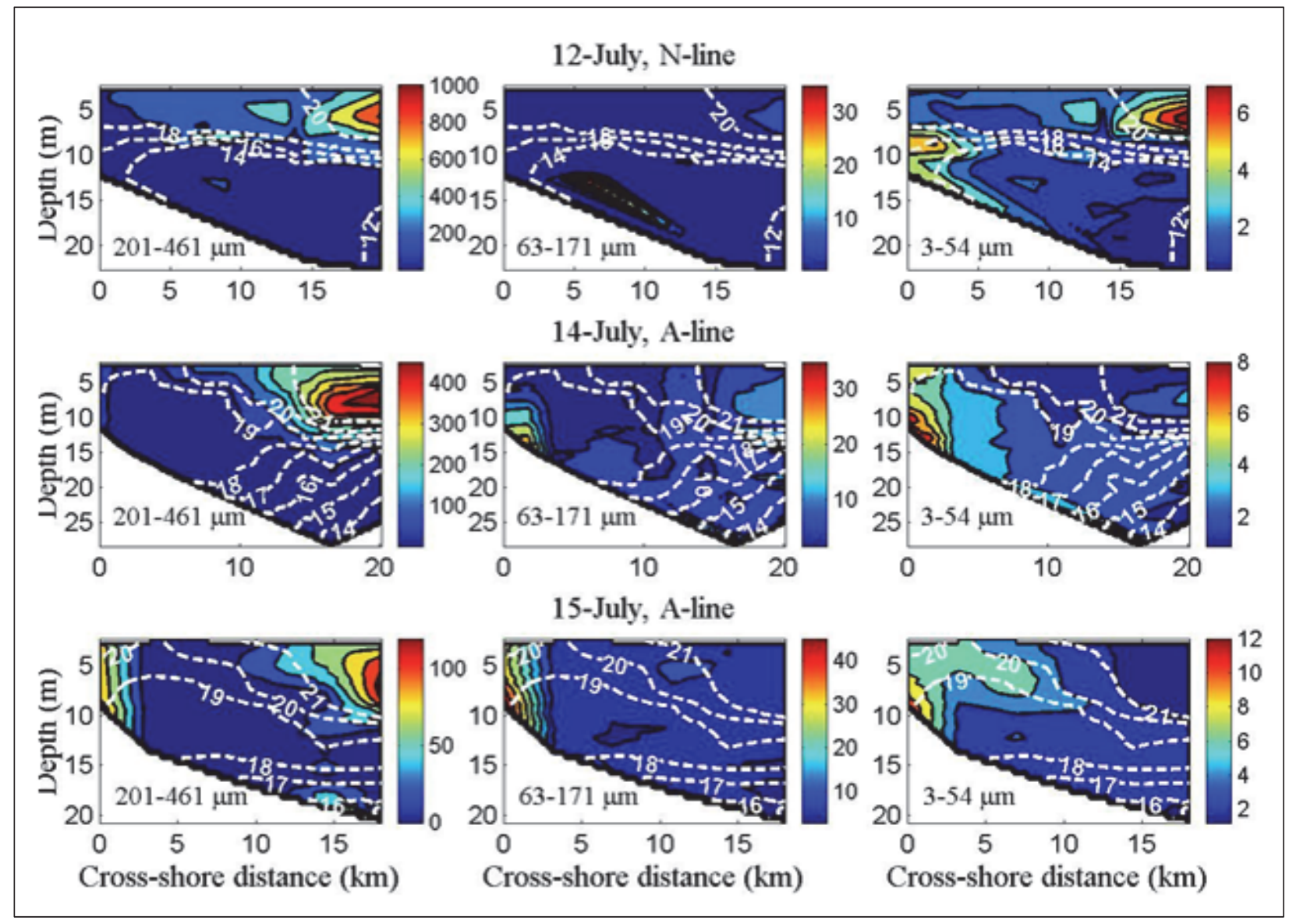




\section{Discussion}

\section{Instruments effects on sampling}

At the offshore stations above the thermocline, the concentration distribution of the largest particles measured by the LISST is not well correlated with the ac-9. Figures 10 and 11 show the LISST downcasts and upcasts, respectively, for the A-line on 12 July 1999. On the downcasts, the ensembles representing the two larger size classes show very narrow particle maximums in the thermocline. The area of highest concentrations is 12 to $15 \mathrm{~km}$ in width and approximately a meter thick. In contrast, the upcasts depict the highest concentrations above the thermocline for the largest and smallest ensembles. The horizontal extent is similar to the downcasts, but the particles are spread over a broader vertical range. Considering that the instrument is sampling the same water mass, upcasts

Figure 10. Cross-shelf transects of concentration along the A-line on 12 July 1999 , as measured by the LISST downcasts.
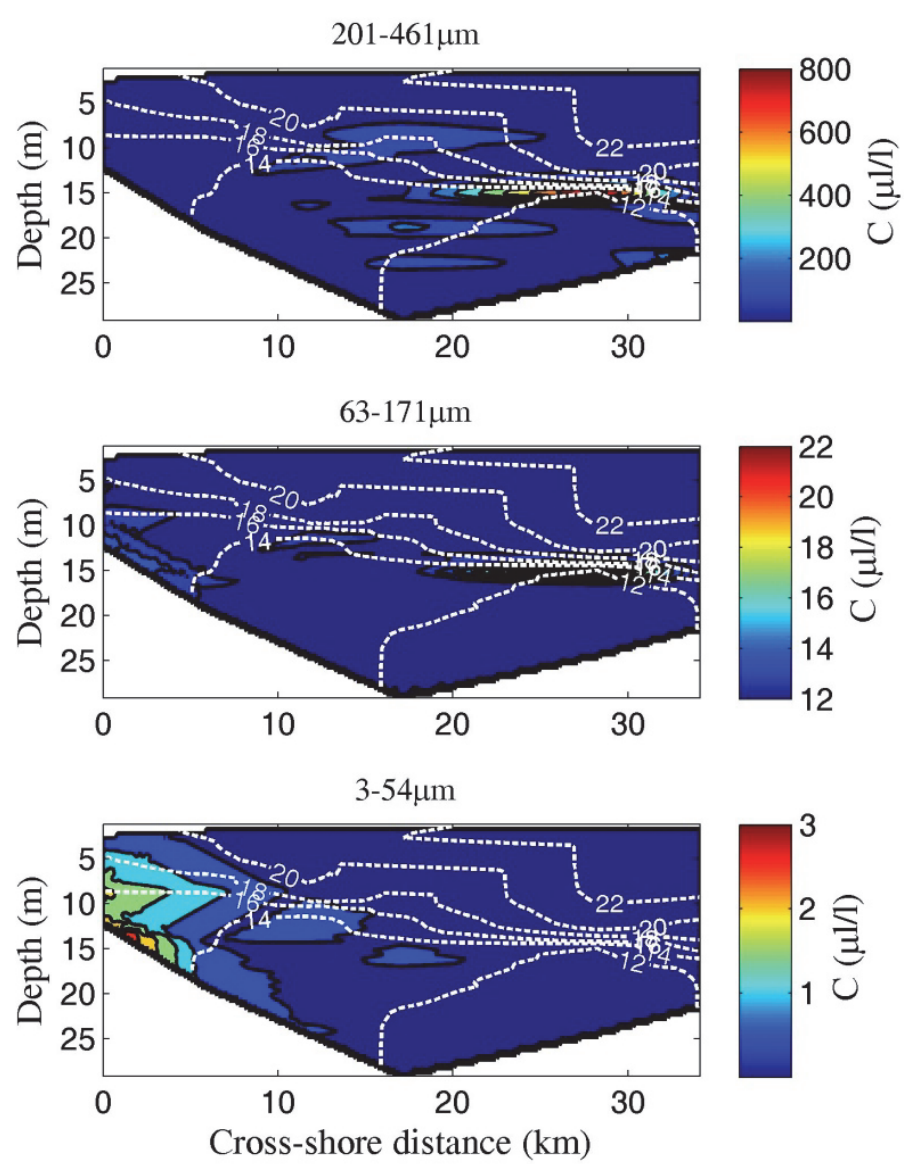
Figure 11. Cross-shore transect of sediment concentration along the A-line on 12 July 1999, as measured by the LISST upcasts.

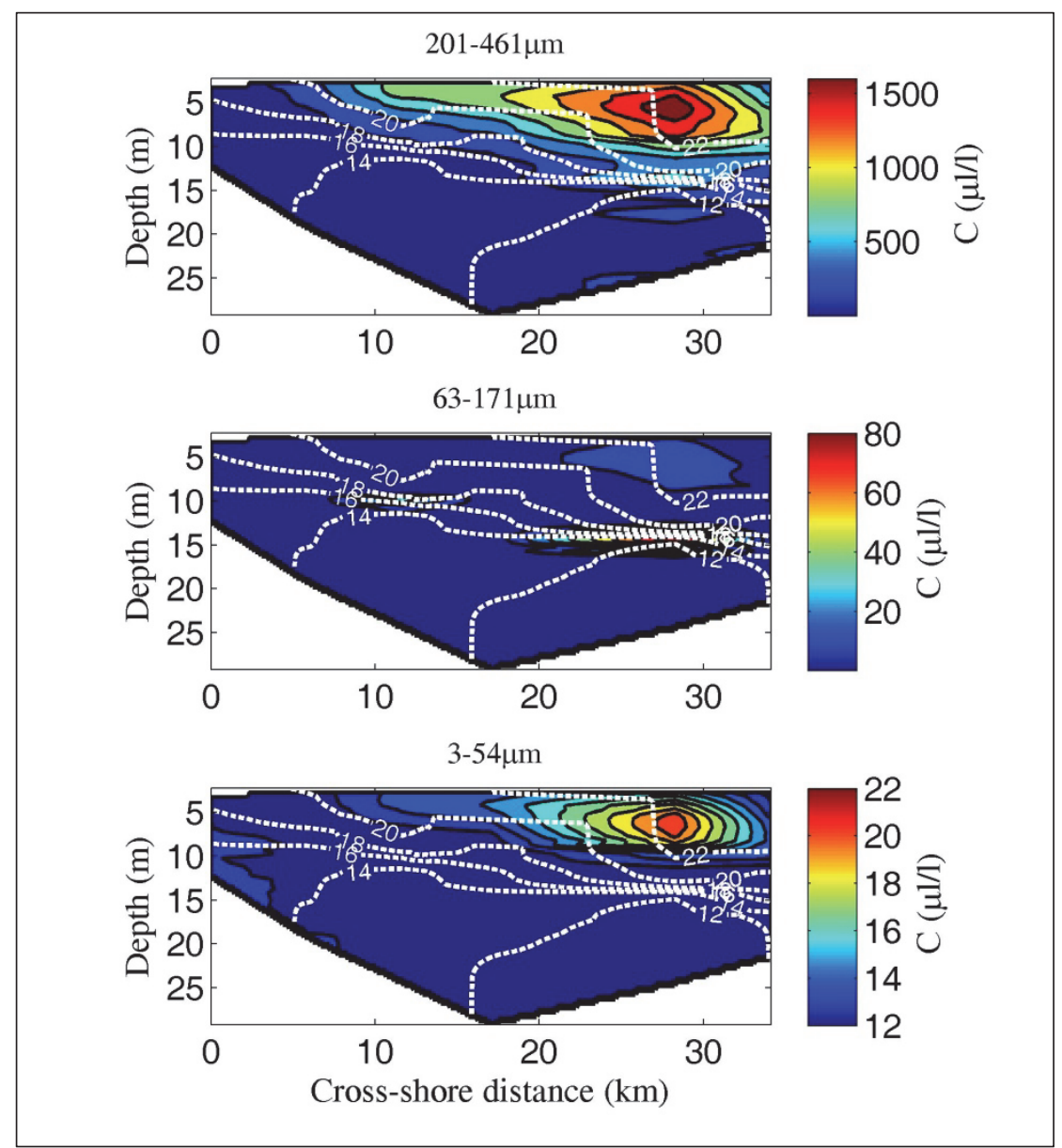

and downcasts should produce nearly the same distribution. The difference is believed to be caused by the placement of the LISST in the sampling cage and by buoyancy and turbulence. The cage housing the instruments is approximately $1.5 \mathrm{~m}$ tall and $1 \mathrm{~m}$ wide. All instruments are placed on the inside of the cage for protection, and the supporting framework is designed to minimize flow interference when in motion. Even so, the superposition of eight sensors, power and communication cables, bracket and clamp supports, and two seawater pumps causes some flow disturbance when raised or lowered through the water column. The vertical motion generates turbulence within the cage interior and a residual wake. The LISST is mounted vertically with the sampling volume near the bottom of the cage. On the downcasts, flow interference is less significant as undisturbed seawater first passes through the LISST sampling volume before it enters the main section of the instrument cage. On the upcasts, the water is forced past the other instruments as well as the superstructure before reaching the LISST sampling volume. This produces an asymmetry in the turbulence, 
with instruments mounted near the bottom of the cage experiencing greater turbulence on the upcasts.

This asymmetry helps explain the differences in the LISST results between the upcasts and downcasts. It is first assumed that the downcasts accurately describe the undisturbed state of the particulate distribution in the water column. The downcasts (Figure 10) show a narrow and highly concentrated layer of the large and medium particle ensembles near the maximum temperature gradient. The thickness and location of the layer indicate that the particles are of intermediate density, being slightly less (greater) than bottom (surface) waters. On the downcast, the LISST samples this layer before the bulk of the cage begins to pass through it. With the exception of some small flow interference from water passing through the sampling volume and ambient turbulence, which is low because of the stably stratified water column, the measurement is undisturbed. Because the density of the particles in the thermocline is less than bottom waters, particles entrained by the cage on the downcast are positively buoyant. This causes the displaced particles to rise upward toward the thermocline where they are neutrally buoyant.On the upcasts, the top of the cage penetrates and disturbs the particle layer. The turbulent eddies induce mixing, and the rising cage temporarily entrains the particles. As the cage continues upward, the entrained particles are denser than the surrounding seawater and begin to sink. An instrument located at the bottom of the cage will measure concentrations dispersed over a greater vertical range before measuring a decrease in concentration as the remainder of the particles sink, and there is no source of particles from above. This process is illustrated in Figure 12. As the cage is lifted through the water, column concentrations near the bottom are relatively low. At the depth of the maximum temperature gradient (concentration maximum on the downcast), concentrations begin to increase as the cage moves upward. Just before the cage reaches the surface, concentrations reach a maximum and then begin to decline. Once the cage reaches its minimum depth, where it remains for about 2 minutes before being retrieved from the ocean, concentrations decay exponentially.

On the upcast, not only is the concentration patch being entrained by the profiling cage, but the particles are disaggregated. For the downcasts (Figure 10), the smallest ensemble shows maximum concentrations inshore of about $3 \mu l / l$ and no noticeable signature in the thermocline. On the upcasts (Figure 11), maximum concentrations of approximately $15 \mu l / l$ are seen offshore above the thermocline. High concentrations in the two largest 
Figure 12. Concentration for selected particle size classes measured on the upcast. The red line is the water depth. As the cage is raised from the bottom $(14.5 \mathrm{~m})$, concentrations decay until approximately $12 \mathrm{~m}$ depth, when they begin to rise. At approximately $5 \mathrm{~m}$ depth, concentrations reach a maximum and then decay as the cage is held near the surface at approximately $2.5 \mathrm{~m}$ depth. The plot illustrates the entrainment mechanism by which larger particles are mixed upward as the sampling cage passes through the thermocline.

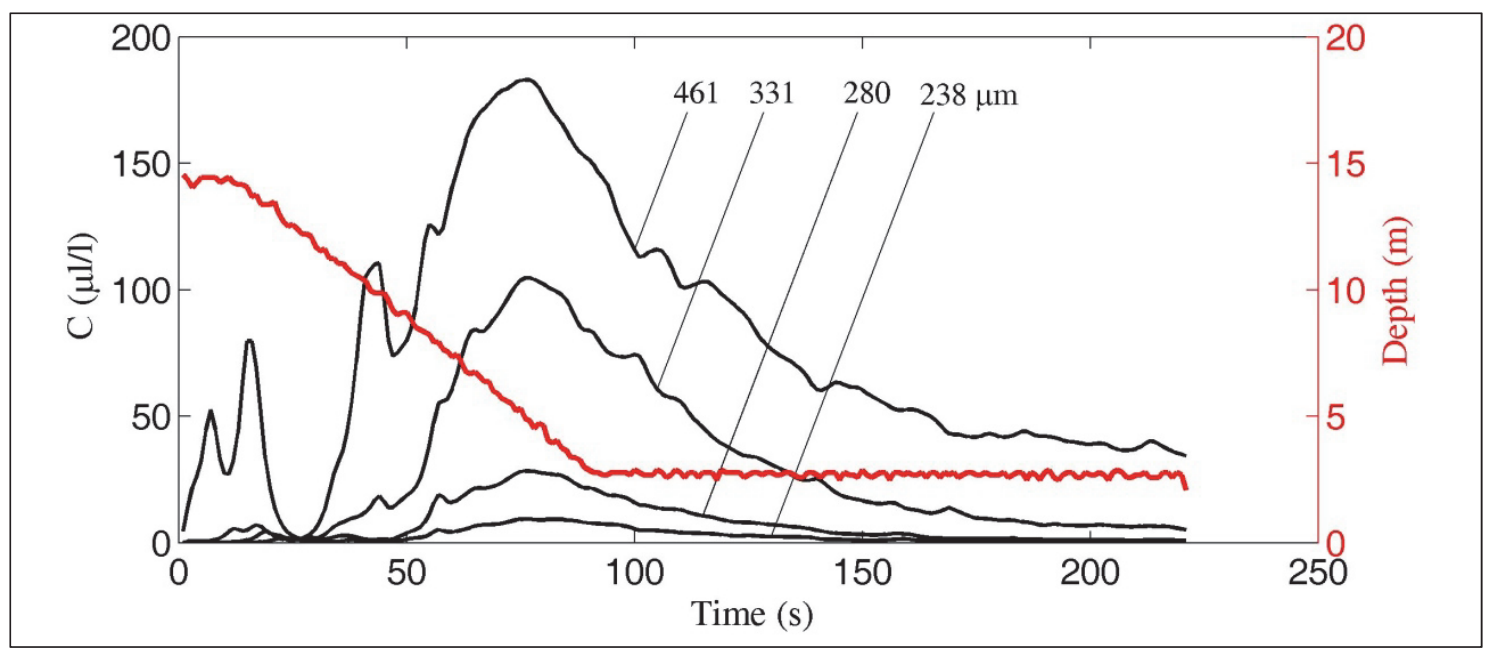

ensembles are observed in the thermocline. Therefore, they must provide the source for the smallest ensemble in the upcasts. A volume concentration balance for each of the three ensembles indicates that vertically integrated concentrations on the upcast are about four times greater than on the downcast. This difference may be explained by the LISST repeatedly sampling some of the same less buoyant disaggregated particles on the upcast as they are being re-entrained by the profiling cage.

The ac-9 attenuation measurements provide further evidence of particle entrainment by the profiling cage (Figure 6). The two offshore stations along the $\mathrm{N}$-line show an increase in attenuation at $442 \mathrm{~nm}$ above the thermocline that is similar to the LISST results. The peak occurs in the upper third of the water column and then decays as the surface is approached. As noted above, the downcast LISST measurements along the A-line on 12 July 1999 do not show higher concentrations at the offshore stations for the smallest size class, but they do show higher values inshore (Figure 10). Although this is most clearly illustrated along the A-line for the LISST, a similar result holds for the N-line. The next section shows that attenuation due to scattering measured by the ac-9 is sensitive to this smallest size class and that the larger particles do not contribute significantly to the measured attenuation signal. Therefore, the increase in attenuation seen in the ac-9 data along the offshore stations results from disaggregation of the larger sized particles to form the smaller size class 
(3 - $54 \mu \mathrm{m})$. The results further indicate that disaggregation is caused by the sampling system and not due to natural processes. Without the aid of the LISST, it would be difficult to accurately interpret the attenuation measured by the ac-9 with respect to the undisturbed physical environment.

Although particle composition cannot be verified on the basis of scattering alone, the ac-9 and LISST measurements do provide insight into the physical properties the particles are likely to possess. The fact that high concentrations of the smallest size class are seen only on the upcast suggests that the patch in the thermocline is composed of flocculated detrital material that is easily disaggregated. Because the patch has a relatively low density compared to minerals, it is also probably organic in origin.

\section{Particle number distribution}

Although the above analysis provides an explanation for the source of high concentrations of particles above the thermocline, the highest correlation between the ac- 9 and the LISST occurred at the inner stations where the water column was well mixed. Total attenuation is the sum of scattering and absorption. The fraction of the attenuation signal due to scattering is a function of particle concentration and particle number. In general, smaller, weakly or non-absorbing particles scatter more light due to their greater abundance. Larger particles have greater concentrations, as volume increases as the cube of the size, but generally have fewer numbers. The fact that attenuation did not correlate well with the high concentrations exhibited by the largest size class suggests that particle number may play more of a role in the scattering characteristics of the particles than concentration.

To determine particle number, it is first assumed that individual particle volume is represented as the cube of the mean particle diameter. Based on this definition, the total particle number for a given volume is equal to the concentration divided by the volume of a single particle size class. This is expressed mathematically in terms of the measurement units for the LISST as $N_{n}={ }_{10}{ }^{3} C_{n} / d_{n}{ }^{3}$, where $N$ is number of particles per $\mu l$, and $d$ is the mean particle size $(\mu \mathrm{m})$ for the $n$th size class. On 14 July 1999, particle number density decreases rapidly as size increases (Figure 13). Since $N$ is linearly proportional to $C$, yet inversely proportional to $d 3$, the small particles with low concentrations dominate the signal. The decrease in particle number density with increase in size means only the smallest particles contribute significantly to the total. 
Figure 13. Total particle number density calculated from profiles collected on 14 July 1999. The number density is divided in terms of onshore (red) and offshore (black) stations. The vertical lines are the same as in Figure 8 and identify the subdivision separating small, medium, and large size classes.

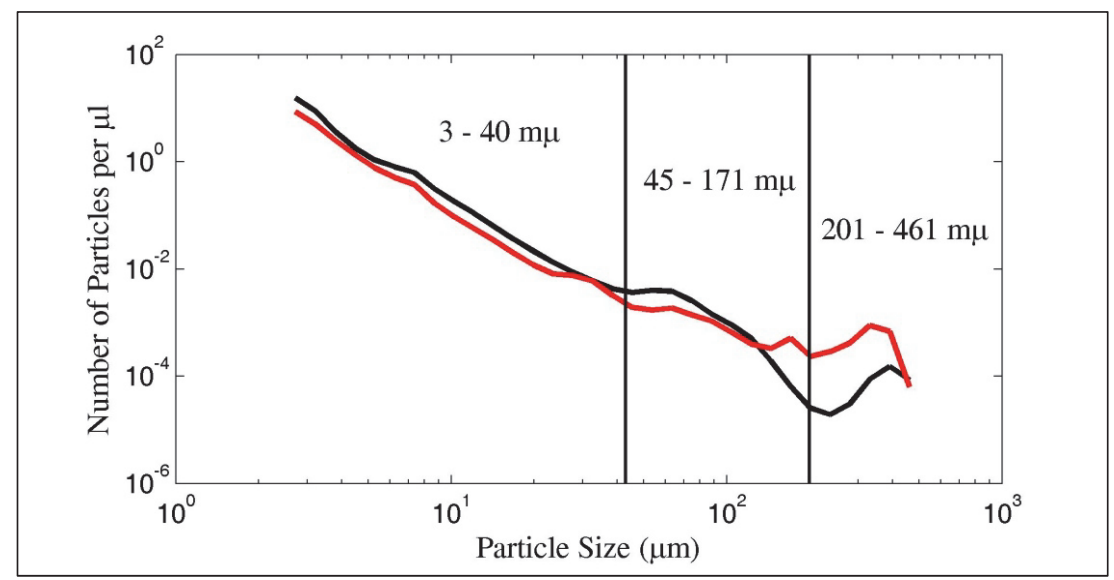

The ac-9 is programmed to sample faster than the LISST, so the data are averaged into synchronized, discrete vertical layers. Five bins per cast are chosen to provide adequate vertical resolution while ensuring enough data points per layer to produce a stable average. A scatter plot of b442 versus the mean of $N_{n}$ sizes in the 3 to $10 \mu \mathrm{m}$ range (Figure 14) reveal a significant correlation $\left(r^{2}=0.87\right)$.

Figure 14. Comparison between scattering at $442 \mathrm{~nm}$ and particle number. Scattering is computed as the difference between the ac-9-measured attenuation and absorption values. The square of the correlation coefficient $(r)$ for the best-fit line is 0.87 .

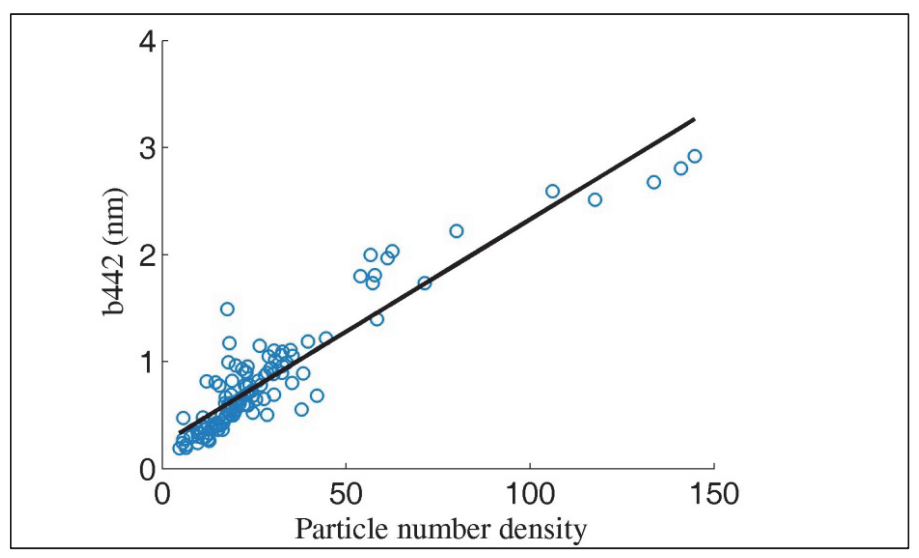

The correlation affirms the role of concentration and size distribution in contributing to the scattering characteristics of particles. Optical instruments that measure suspended sediment concentrations, such as OBS, have responses that drop off inversely as a function of particle size (Traykovski et 
al. 1999), with maximum intensity corresponding to particles on the order of the wavelength of the light. For an OBS, this occurs for particle sizes of about $1 \mu \mathrm{m}$. The wavelength dependence is stronger than the linear dependence to concentration so that high concentrations of larger particles in the presence of small ones are less likely to be detected than in a more homogeneous environment. The wavelengths produced by the ac- 9 are on the order of $0.1 \mu \mathrm{m}$, which is closest in scale to the smallest particles $(1 \mu \mathrm{m})$ measured by the LISST, and explains why the LISST and ac-9 show highest correlation for the smallest size class.

Optical design is also important in quantifying and understanding the scattering characteristics of a heterogeneous distribution of particle sizes (Voss and Austin 1993). The ac-9 has a larger angle of acceptance (aperture) than the LISST. Light scattered from larger particles at forward scattering angles narrower than the aperture of the ac-9 are interpreted as transmitted light. The dynamic range of the LISST is designed to measure particles up to $500 \mu \mathrm{m}$, giving the LISST a smaller aperture. Light scattered from these same larger particles falls on the surface of the LISST detector and are recorded as scattered light. Therefore, the LISST is able to measure the largest particle sizes, while the ac-9 groups these in the transmitted signal, and so their scattering signature remains undetected.

These results show the importance of using a suite of precision instruments that measure different optical properties to reveal and accurately interpret the particle spectrum of optically complex coastal waters. The discussion also raises questions as to the optical relevance of the larger, higher-concentration particles. In particular, resuspension of fine to medium sands in the bottom boundary layer may not be very significant relative to radiative transfer, but it is important in terms of sediment transport. 


\section{Conclusions}

High-resolution, cross-shelf physical and bio-optical ship surveys were conducted at the LEO site during the summer stratified season. Attenuation, scattering, and LISST measurements point to increased particle concentrations at depths less than approximately $15 \mathrm{~m}$ a day after a storm passed over the study area. Concentration estimates obtained with a LISST showed asymmetries between upcasts and downcasts in the thermocline. This asymmetry was attributed to the interaction between profiling cage-induced turbulence, buoyancy, and the position of the LISST within the cage framework. The thickness of the particulate layer based on the upcasts is exaggerated compared to the undisturbed thermocline. Particle number density for the smallest fraction $(<6 \mu \mathrm{m})$ obtained from the LISST compared well with scattering at $442 \mathrm{~nm}$ from the ac-9. Consequently, only the smallest fraction contributes significantly to particle scattering in this region during the experiment. Optical design inhibited the ac-9 from being able to detect the presence of the larger particles. 


\section{References}

Agrawal, Y. C., and H. C. Pottsmith. 2000. Instruments for particle size and settling velocity observations in sediment transport. Mar. Geol. 168:89-114.

Agrawal, Y. C., and P. Traykovski. 2000. Particles in the bottom boundary layer: Concentration and size dynamics through events. J. Geophys. Res. 106:95339542.

Boss, E., W. S. Pegau, W. D. Gardner, J. R. V. Zaneveld, A. H. Barnard, M. S. Twardowski, G. C. Chang, and T. D. Dickey. 2001. Spectral particulate attenuation and particle size distribution in the bottom boundary layer of a continental shelf. J. Geophys. Res. 106:9509-9516.

Chang, G. C., T. D. Dickey, and A. J. Williams III. 2001. Sediment resuspension over a continental shelf during hurricanes Edouard and Hortense. J. Geophys. Res. 106:9517-9531.

Dickey, T. D., and A. J. Williams, III. 2001. Interdisciplinary ocean process studies on the New England shelf. J. Geophys. Res. 106:9427-9434.

Glenn, S. M., T. D. Dickey, B. Parker, and W. Boicourt. 2000. Long-term real-time coastal ocean observation networks. Oceanography 13:24-34.

Kennett, J. 1982. Marine geology. Englewood Cliffs, NJ: Prentice-Hall.

Mobley, C. D. 1994. Light and water radiative transfer in natural waters. San Diego, CA: Academic Press.

Moline, M. A., R. Arnone, T. Bergmann, S. Glenn, M. Oliver, C. Orrico, O. Schofield, and S. Tozzi. 2004. Variability in spectral backscatter estimated from satellites and its relation to in-situ measurements in optically complex coastal waters.

International Journal of Remote Sensing 25:1465-1468.

Neter, J., W. Wasserman, and M. H. Kutner. 1989. Applied Linear Regression Models, $2^{\text {nd }}$ ed. Boston, MA: Irwin.

Schofield, O., J. Grzymski, P. Bissett, G. Kirkpatrick, D. F. Millie, M. A. Moline, and C. Roesler. 1999. Optical monitoring and forecasting systems for harmful algal blooms: Possibility or pipedream? J. Phycology 35:125-145.

Schofield, O., T. Bergmann, P. Bissett, J. Grassle, D. Haidvogel, J. Kohut, M. Moline, and S. M. Glenn. 2002. The long-term ecosystem observatory: An integrated coastal observatory. J. Oceanic Engineering 27:146-154.

Sosik, H. M., R. E. Green, W. S. Pegau, and C. S. Roesler. 2001. Temporal and vertical variability in optical properties of New England shelf waters during late summer and spring. J. Geophys. Res. 106:9455-9472.

Sullivan, J. M., L. P. Donaghay, J. E. B. Rines. 2010. Coastal thin layer dynamics: Consequences to biology and optics. Cont. Shelf Res. 30:50-65. 
Traykovski, P., A. E. Hay, J. D. Irish, and J. F. Lynch. 1999. Geometry, migration, and evolution of wave orbital ripples at LEO-15. J. Geophys. Res. 104:1505-1524.

Twardowski, M. S., J. M. Sullivan, P. L. Donaghay, and J. R. V. Zaneveld. 1999. Microscale quantification of the absorption by dissolved and particulate material in coastal waters with an ac-9. J. Atmos. Oceanic Technol. 16:691-707.

von Alt, C. J., and J. F. Grassle. 1992. LEO-15: An unmanned long-term environmental observatory. In Proceedings, Oceans 92, 26-29 October, 849-854. Newport, Rhode Island; Piscataway, New Jersey.

Voss, K. J., and R. W. Austin. 1993. Beam-attenuation measurement error due to smallangle scattering acceptance. J. Atmos. Oceanic Tech. 10:113-121. 


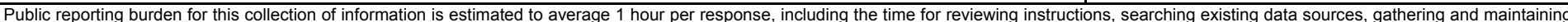

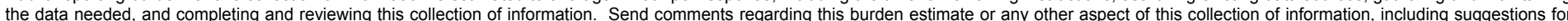

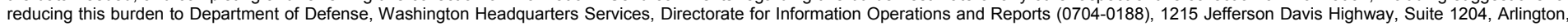

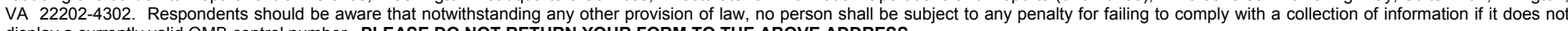
display a currently valid OMB control number. PLEASE DO NOT RETURN YOUR FORM TO THE ABOVE ADDRESS.

\begin{tabular}{l|l|l}
$\begin{array}{l}\text { 1. REPORT DATE (DD-MM-YYYY) } \\
\text { November } 2013\end{array}$ & $\begin{array}{l}\text { 2. REPORT TYPE } \\
\text { Final }\end{array}$ & 3. DATES COVERED (FrOm - To)
\end{tabular}

\section{TITLE AND SUBTITLE}

5a. CONTRACT NUMBER

Particle Size Distributions and Attenuation on a Stratified Inner Continental Shelf

5b. GRANT NUMBER

5c. PROGRAM ELEMENT NUMBER

\section{AUTHOR(S)}

Richard Styles

\section{5d. PROJECT NUMBER}

5e. TASK NUMBER

\section{5f. WORK UNIT NUMBER}

8. PERFORMING ORGANIZATION REPORT NUMBER

ERDC/CHL TR-13-14

Coastal and Hydraulics Laboratory

3909 Halls Ferry Rd

Vicksburg MS 39180

\section{SPONSORING / MONITORING AGENCY NAME(S) AND ADDRESS(ES)}

10. SPONSOR/MONITOR'S ACRONYM(S)

Coastal and Hydraulics Laboratory

US Army Engineer Research and Development Center

3909 Halls Ferry Road, Vicksburg, MS 39180
11. SPONSOR/MONITOR'S REPORT NUMBER(S)

\section{DISTRIBUTION / AVAILABILITY STATEMENT}

Approved for public release; distribution is unlimited.

\section{SUPPLEMENTARY NOTES}

\section{ABSTRACT}

High resolution, cross-shelf physical and bio-optical ship surveys were conducted during the summer stratified season off the southern coast of New Jersey. On 13 July 1999, a small storm passed over the study area generating the largest waves of the summer field season. Compared to pre-storm levels, scattering measured with an Attenuation-Scattering at 9 wavelengths sensor (ac-9) in depths less than 15 $\mathrm{m}$ doubled on 14 July 1999. This increase was accompanied by strong vertical mixing inshore and increases in suspended sediment concentrations measured with a Laser In Situ Scattering Transmissometer (LISST-100). A particulate load maximum was observed offshore in the thermocline. The location and vertical distribution of the maximum was unexpectedly asymmetric between the up and downcasts. The observations indicated that the asymmetry was caused by particle entrainment, disaggregation, and mixing by the sampling cage housing the instruments as it was lowered and raised through the water column. A method to remove the profiling effect appeared to accurately reproduce the concentration and vertical distribution of suspended particles. The measurements suggested that some of the larger entrained particles were disaggregated to form concentrations of smaller particles on the upcasts. Given the location of the LISST within the profiling sea cage, only the downcasts produced undisturbed estimates of the vertical distribution of concentration and size classes.

\begin{tabular}{|c|c|c|c|c|c|}
\hline 15. SUBJECT TEF & & Stratification & \multicolumn{3}{|c|}{ Instrumentation } \\
\hline Continental She & & Particle Dynamics & \multicolumn{3}{|c|}{ Field Study } \\
\hline Thermocline & & Coastal Optics & \multicolumn{3}{|c|}{ Summer Storm } \\
\hline \multicolumn{2}{|c|}{ 16. SECURITY CLASSIFICATION OF: } & & $\begin{array}{l}\text { 17. LIMITATION } \\
\text { OF ABSTRACT }\end{array}$ & $\begin{array}{l}\text { 18. NUMBER } \\
\text { OF PAGES }\end{array}$ & $\begin{array}{l}\text { 19a. NAME OF RESPONSIBLE } \\
\text { PERSON Richard Styles }\end{array}$ \\
\hline $\begin{array}{l}\text { a. REPORT } \\
\text { unclassified }\end{array}$ & $\begin{array}{l}\text { b. ABSTRACT } \\
\text { unclassified }\end{array}$ & $\begin{array}{l}\text { c. THIS PAGE } \\
\text { Unclassified }\end{array}$ & Unclassified & 30 & $\begin{array}{l}\text { 19b. TELEPHONE NUMBER (include } \\
\text { area code) } \\
601-634-4065\end{array}$ \\
\hline
\end{tabular}

